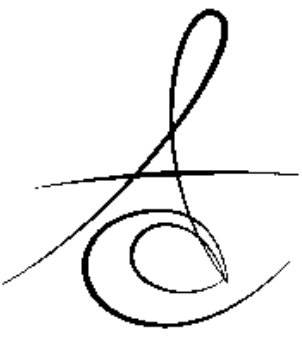

Makale Kodu/Article code: 3319

Makale Gönderilme tarihi: 24.01 .2017

Kabul Tarihi; 29.03.2017

\section{SİLİKON ESASLI YUMUŞAK ASTAR MATERYALLERİNDE BEKLETME SÜRELERİNİN SERTLİK VE SU EMİLİMİ ÜZERİNE ETKİSİ}

\section{THE EFFECT OF STORAGE TIMES ON THE HARDNESS AND WATER SORPTION IN SILICONE-BASED SOFT LINING MATERIALS}

Dr. Öğr. Üyesi Faik TUĞUT*

Dr. Öğr. Üyesi Türker AKAR**

\section{öz}

Amaç: Bu çalışmanın amacı, silikon esaslı yumuşak astar materyalinin su içerisinde bekletme sürelerinin maddenin sertliği ve su emilimi üzerine etkisini araştırmaktır.

Gereç ve Yöntem: Çalışmada silikon esaslı yumuşak astar maddesi Permaflex ve aynı maddenin izobutilmetakrilat likit ilave edilmiş formu kullanıldı. Yumuşak astar materyalleri üretici talimatlarına uygun olarak su emilimi testleri için $(10 \times 10 \times 1 \mathrm{~mm})$ boyutlarında, sertlik testleri için ise $(10 \times 10 \mathrm{~mm})$ boyutlarında hazırlandı ve $37{ }^{0} C^{\prime}$ lik su banyosu içerisinde bekletildi. 1. gün, 1 . hafta, 1,3 ve 6 aylık süre zarflarında su emilim ve Shore A sertlik değerleri ölçümleri gerçekleştirildi. Veriler Man Whitney $U$ testi, Friedman testi ve Wilcoxon testi kullanılarak belirlendi ( $a=0.05)$.

Bulgular: Sertlik değerleri bakımından, Permaflex ve Permaflex+izobutilmetakrilat grupları arasında tüm zaman dilimleri kıyaslandığında istatistiksel olarak anlamlı fark tespit edilmiştir $(p<0,05)$. Su emilim değerleri arasında da sadece 3. ay ölçümlerinde istatistiksel olarak fark tespit edilmiştir $(p<0,05)$. Permaflex grubunun su emilim değeri Permaflex+izobutilmetakrilat grubundan istatistiksel olarak anlamlı derecede yüksek olarak tespit edilirken daha düşük sertlik değerine sahip olduğu bulunmuştur. Suda bekletilme süreleri boyunca hem Permaflex hem de Permaflex+izobutilmetakrilat gruplarının su emilim değerlerinde artış görülürken, sertlik değerlerinde istatistiksel olarak önemli bir artış tespit edilmemiştir.

Sonuç: İzobutilmetakrilat'ın ve farklı zaman dilimlerinde bekletmenin sertlik ve su emilimi açısından yumuşak astar maddesi üzerinde değişikliğe sebep olduğu belirlendi.

Anahtar Kelimeler: Yumuşak astar maddesi, izobutilmetakrilat, sertlik, su emilimi.

\section{ABSTRACT}

Aim: The purpose of this research is to investigate the effect of the storage times of silicone-based soft lining material in water on hardness and water absorption of the material.

Material and methods: In this study, silicone based soft denture liner Permaflex and isobutylmethacrylateadded form of the same material were used. The soft denture liners were processed according to manufacturers' instructions with the dimension $(10 \times 10 \times 1 \mathrm{~mm})$ for water sorption tests and $(10 \times 10 \mathrm{~mm})$ for hardness tests, and then put in water bath at $37{ }^{\circ} \mathrm{C}$. During the periods of $1^{\text {st }}$ day, $1^{\text {st }}$ week, 1,3 and 6 months, the measurements of water absorption and Shore $A$ hardness values were performed. Data were evaluated using Man Whitney $U$, Friedman and Wilcoxon tests $(a=0.05)$.

Results: Regarding the hardness, a statistically significant difference was obtained among all Permaflex and Permaflex+isobutylmethacrylate groups when comparing all time periods $(p<0,05)$. A statistically significant difference was also found between the water absorption values only at the $3^{\text {rd }}$ month measurements $(p<0,05)$. In Permaflex group, water absorption value was statistically higher and hardness values were statistically lower compared to Permaflex+ isobutylmethacrylate groups. While the water absorption values of both Permaflex and Permaflex + isobutylmethacrylate groups increased during the water holding periods, no statistically significant increase in hardness values was found.

Conclusion: It has been determined that isobutylmethacrylate and storage in different time periods cause a change in the soft lining material in terms of hardness and water absorption.

Keywords: Soft lining materials, Isobutylmethacrylate, hardness, water sorption

${ }^{*}$ Cumhuriyet Üniversitesi, Dişhekimliği Fakültesi, Protetik Diş Tedavisi AD, Sivas

${ }^{* *}$ Erzincan Üniversitesi, Diş Hekimliği Fakültesi, Protetik Diş Tedavisi AD, Erzincan 


\section{GİRIŞ}

Yumuşak astar materyalleri protez alanında, travmatize oral mukoza, bruksizm, kronik ağrı, alveolar kemiğin atrofisi ve rezorbsiyonu sonucu oluşan ince ve rezilient olmayan mukozada, kemik andırkatlarında ve doğumsal yada sonradan oluşan ağız defektlerinin obturasyonunda kaidenin altını tamamen örtüp yastık görevi olarak kullanılan malzemelerdir. ${ }^{1-4}$ Bunun yanı sıra yumuşak astar materyalleri implant cerrahisi sonrası geçici protezlerin altında da kullanılabilir. ${ }^{5} \mathrm{Bu}$ materyaller ağız mukozası ile temas ettiğinde gelen okluzal kuvvetlerin bir kısmını kendi içerisinde absorbe ederken arta kalan yüklerin homojen olarak dağıtılmasını sağlar. ${ }^{4}$

Yumuşak astar materyalleri, akrilik esaslı ve silikon esaslı olmak üzere 2 gruba ayrılır ${ }^{2,6}$ Akrilik esaslı olanların yapısında plastizer bulunurken zamanla bu plastizerin uzaklaşması sonucu astar materyalinde sertleşme gerçekleşir. Silikon esaslı yumuşak astar materyalinin yapısında polimer yapılı elastomer olduğundan ilave plastizer yapıya ihtiyaç duymaz, bu yüzden uzun süre esnekliğini korur. Ayrıca bu materyallerin ISI veya otopolimerizan olarak sertleşebilen çeşitleri de mevcuttur. ${ }^{7,8}$

Klinik çalışmalarda, yumuşak astar materyalleri tükrük, su ve temizleme ajanlarında bekletildiğinde bir miktar emilimin gerçekleştiği ve yapısındaki plastizer ve çözünebilir ajanların ortama sızdığı belirtilmiştir. Malzeme içerisindeki plastizer miktarındaki azalma sonucunda malzemenin sertliğinde bir artış ve uzama katsayısında bir azalmanın oluştuğu vurgulanmıştır. ${ }^{4,7-11}$ Yumuşaklığını kaybeden astar materyalleri mukozaya iletilen kuvvetlerin artmasına ve klinik şikayetlerin çoğalmasına neden olabilmektedir. ${ }^{7}$

Protez kaidesi ile yumuşak astar materyali arasındaki bağlantının sürekliliği protezin fonksiyonu gerçekleştirmesinde önemli bir etkendir. Bu bağlantı kuvvetinin artırılması amacıyla akrilik yüzeyine lazer, kumlama ve kimyasal ajan uygulanımları gerçekleştirilmektedir. ${ }^{1,4,11-14}$ Tercih edilebilecek kimyasal ajanlardan birisi olan izobutilmetakrilat akrilikle olan bağlanma kuvvetini artırırken akriliğin fiziksel özelliklerini de artırmaktadır. ${ }^{13,14}$ İzobutilmetakrilat karıştırıldığı rezin içerisinde çözücü, örtücü ve yapıştırıcı olarak görev yaptığı için tekstil sanayisinde de uygulama alanlarına sahiptir. Diş hekimliğinde de polimetilmetakrilat (PMMA) esaslı kaide materyalinin mekanik özellikleri$\mathrm{ni}^{15,16}$ ve PMMA ile yumuşak astar materyalleri arası bağlanma kuvvetini artırmak için kullanılmıştır. ${ }^{13,14}$ Butil metakrilatın polimer matriks içerisindeki birleşimi ve dağılımı sayesinde meydana gelen yüzeyler arasında güçlü etkileşim sayesinde maddeye hidrofobik özellik kazandırdığı ifade edilmektedir. ${ }^{15,16}$ Ayrıca izobutil metakrilatın, PMMA içerisine katılarak kopolimer oluşturduğu yapıda sitotoksik etkisinin olmadığı belirtilmektedir. ${ }^{16}$ Bütün bu özelliklerinden dolayı çalışmamızda izobutilmetakrilat monomer kullanımı tercih edilmiştir.

Yumuşak astar materyallerinin farklı ortamlar içerisinde bekletilerek bağlanma dayanımı, su emilimi ve sertlik değerlerinin tespitine yönelik çalışmalar literatürde mevcuttur. . ${ }^{4,9,10,14,17}$ Ancak izobutilmetakrilat ilavesinin yumuşak astarların fiziksel özellikler üzerine uzun süreli etkisinin araştırıldığı çalışmalar noktasında literatürde eksiklik bulunmaktadır. Bu sebeple çalışmamızda Isı ile polimerize olan silikon esaslı yumuşak astar materyalinin farklı zaman dilimlerinde su emilimi ve sertliğinin incelenmesi amaçlandı. Ayrıca çalışmamızda farklı zaman dilimlerinde su içerisinde bekletmenin yumuşak astar maddesinin su emilimi ve sertliği üzerine etkisi yoktur hipotezi test edilmiştir.

\section{GEREÇ VE YÖNTEM}

Çalışmada ISı ile polimerize olan silikon esaslı yumuşak astar maddesi (Permaflex (PERMA), Kohler, Neuhausen, Almanya) ve izobutilmetakrilat (iBMA) (Sigma-Aldrich Chemie $\mathrm{GmbH}$, Buchs, İsviçre) likiti kullanıldı. Su emilimi testi için ISO Standartı 1567: 1999'a uygun olarak (10x10x1mm) boyutlarında, sertlik testi için $(10 \times 10 \mathrm{~mm})$ silindir paslanmaz metal kalıplar hazırlandı. Bu kalıplardan her bir grup için 10'ar mum örnek hazırlandı. Mum örnekler muflaya alındı. Sıcak suda mum uçurulup yumuşak astar maddesi için yer sağlandı. Üretici firmanın talimatlarına uygun olarak yumuşak astar maddesi boşluğa yerleştirildikten sonra polimerizasyonu sağlandı.

PERMA+iBMA grubunda ise numune hazırlanmasında 10 gr PERMA' nın üzerini tamamen kapatacak şekilde (10 cc) iBMA monomeriyle birlikte bir bardak içerisine yerleştirilip 3 dakika bekletilmesi prosedürü uygulandı. Daha sonra bardaktan çıkarılarak muflada hazırlanan boşluklara yerleştirildi. Firmanın talimatlarına uygun olarak polimerizasyonu sağlandı.

Su emiliminde kullanılan örnekler polimerize edildikten sonra hassas terazi ile tartıldı. Hazırlanan

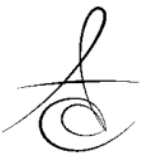


örnekler silika jel içeren desikatörde bekletildi. Örneklerde $( \pm 0.5 \mathrm{mg})$ dan fazla ağırlık azalması olmayıncaya kadar işlemler tekrarlandı. Kuruyan örneklerin tartımı yapıldı ve değerleri yazıldı. Sonra örnekler su banyosunda (Nüve BM302, Ankara, Türkiye) sıcaklığı $37 \pm 1^{\circ} \mathrm{C}$ olan distile su içerisinde bekletildi. 1. gün, 1 . hafta, 1,3 ve 6 . aylarda örnekler su banyosundan çıkarılıp kurutma kağıdıyla kurutulduktan sonra tartılıp ağırlıkları kaydedildi.

Tüm örneklerin su emilim değerleri şu formülle hesaplandı:

Su emilimi $=M 2-M 1(\mathrm{~g}) / \mathrm{S}\left(\mathrm{cm}^{3}\right)$

Sertlik testinde kullanılacak örnekler su banyosu cihazında sıcaklığı $37 \pm 1^{\circ} \mathrm{C}$ olan distile su içerisinde bekletildi. 1. gün, 1 . hafta, 1,3 ve 6 . aylarda örnekler çıkarılıp sertlik değerleri kaydedildi. Sertlik değerleri ASTM D2240'a göre kalibre edilen, Shore A (Tronic, Kore) ölçüm cihazı yardımıyla gerçekleştirildi. Her örnek için beş farklı bölgeden ölçüm işlemi tekrar edildi ve elde edilen verilerin ortalaması alındı.

Çalışmada elde edilen verileri SPSS (Ver:22.0) programına yüklenerek hesaplamalar gerçekleştirildi. Verilerin değerlendirilmesinde Man Whitney $U$ testi, Friedman testi ve Wilcoxon testi kullanıldı. Verilerimiz tablolarda aritmetik ortalama $(X) \pm$ standart sapma (SS) şeklinde belirtilip yanılma düzeyi 0,05 olarak alındı.

\section{BULGULAR}

Perma ve Perma+iBMA'lı örneklerin, farklı zaman dilimlerindeki su emilim değerlerinin ortalama ve standart sapma değerleri Tablo 1 ve Grafik 1'de, sertlik değerlerinin ortalama ve standart sapma değerleri Tablo 2 ve Grafik 2'de gösterilmiştir. Sertlik yönünden hem Perma hem de Perma+iBMA grupları kendi içerisinde kıyaslandığında farklılık istatistiksel olarak anlamsız olarak bulunmuştur $(p>0,05)$. Her iki grupta aynı zaman dilimlerinde karşılıklı olarak kıyaslandığında tüm zaman dilimlerinde farklılık istatistiksel olarak anlamlı bulunmuştur $(p<0,05)$. Perma+iBMA grubu tüm zaman dilimlerinde Perma grubuna göre daha yüksek sertlik değerlerini göstermiştir. Başlangıç ve son sertlik ölçümleri arasında en yüksek sertlik artışı Perma grubunda tespit edilmesine rağmen istatistiksel olarak anlamsız bulunmuştur ( $p>0,05)$.

Su emilimi yönünden her bir grup kendi içerisinde değerlendirildiğinde Perma grubunda tüm zaman dilimleri arasında istatistiksel olarak anlamlı fark bulunurken, Perma+iBMA grubunda 1. hafta ile 1 . ay dışındaki diğer ölçümler arasında istatistiksel olarak anlamlı bir fark bulunmuştur $(p<0,05)$. Her iki grupta da bekletme sürelerinin artışı ile su emilim miktarının arttığı görülmüştür. En yüksek artış perma grubunda ve 6 . ayda $(0,0034 \pm 0,0012)$ bulunmuştur. Her iki grup aynı zaman dilimleri itibariyle kıyaslandığında 3. aydaki farklılık istatistiksel olarak anlamlı bulunmuş $(p<0,05)$, diğer zaman dilimlerindeki fark istatistiksel olarak anlamsız bulunmuştur ( $p>0,05)$. Perma grubu iBMA grubuna göre tüm zaman dilimlerinde daha yüksek su emilimi göstermiştir.

Tablo 1. Farklı zaman dilimlerinde gruplara ait su emilimi değerleri $\left(\mathrm{g} / \mathrm{cm}^{3}\right)$

\begin{tabular}{|c|c|c|c|}
\hline & $\begin{array}{c}\text { Perma } \\
\mathrm{X}+\mathrm{SS}\left(\mathrm{g} / \mathrm{cm}^{3}\right) \\
\end{array}$ & $\begin{array}{l}\text { Perma+iBMA } \\
\mathrm{X}+\mathrm{SS}\left(\mathrm{g} / \mathrm{cm}^{3}\right) \\
\end{array}$ & p \\
\hline 1 gün & $0,0002 \pm 0,001^{a, b, c, c, d, A}$ & $0,0003 \pm 0,001^{a, b, c, d, B}$ & 0,080 \\
\hline 1 hafta & $0,0007 \pm 0,0002^{\mathrm{a}, \mathrm{e}, \mathrm{f}, \mathrm{g}, \mathrm{A}}$ & $0,0006 \pm 0,0001^{a, e, f, b}$ & 0,593 \\
\hline 1 ay & $0,0006 \pm 0,0002^{\mathrm{b}, \mathrm{e}, \mathrm{h}, \mathrm{h}, \mathrm{A}}$ & $0,0005 \pm 0,0001^{b, g, h, B}$ & 0,190 \\
\hline 3 ay & $0,0015 \pm 0,0004^{\mathrm{c}, \mathrm{f}, \mathrm{h}, \mathrm{j}, \mathrm{A}}$ & $0,0011 \pm 0,0002^{c, e, g, l, A}$ & $0,012^{*}$ \\
\hline 6 ay & $0,0034 \pm 0,0012^{\mathrm{d}, \mathrm{g}, 1, \mathrm{j}, \mathrm{A}}$ & $0,0026 \pm 0,0008^{d, f, g, h, l, B}$ & 0,068 \\
\hline & $\begin{array}{l}\mathrm{X}^{2}=46,39 \\
\mathrm{p}=0,001 *\end{array}$ & $\begin{array}{l}\mathrm{X}^{2}=47,08 \\
\mathrm{p}=0,001 *\end{array}$ & \\
\hline
\end{tabular}

Her bir dikey sütunda aynı küçük harflerle gösterilen ortalamalar fark istatistiksel olarak anlamlıdır $(p<0,05)$.

* Her bir yatay sütunda aynı büyük harflerle gösterilen ortalamalar arası fark istatistiksel olarak anlamlıdır $(p<0,05)$.

Tablo 2. Farklı zaman dilimlerinde gruplara ait sertlik değerleri

\begin{tabular}{|c|c|c|c|}
\hline & $\begin{array}{c}\text { Perma } \\
\text { X+SS }\end{array}$ & $\begin{array}{c}\text { Perma+iBMA } \\
\text { X+SS }\end{array}$ & $\mathbf{p}$ \\
\hline Tepim & $44,25 \pm 1,89^{\mathrm{a}, \mathrm{A}}$ & $55,37 \pm 1,96^{a, A}$ & $<0,001^{*}$ \\
\hline 1 gün & $46,04 \pm 1,75^{\mathrm{b}, \mathrm{A}}$ & $55,33 \pm 1,55^{b, A}$ & $<0,001^{*}$ \\
\hline 1 hafta & $46,12 \pm 1,62^{\mathrm{c}, \mathrm{A}}$ & $53,87 \pm 2,11^{\mathrm{C}, \mathrm{A}}$ & $<0,001^{*}$ \\
\hline 1 ay & $45,16 \pm 1,02^{\mathrm{d}, \mathrm{A}}$ & $54,91 \pm 1,97^{\mathrm{d}, \mathrm{A}}$ & $<0,001^{*}$ \\
\hline 3 ay & $45,83 \pm 1,43^{\mathrm{e}, \mathrm{A}}$ & $54,41 \pm 1,22^{\mathrm{e}, \mathrm{A}}$ & $<0,001^{*}$ \\
\hline 6 ay & $46,29 \pm 1,42^{f, A}$ & $55,70 \pm 2,0^{f, A}$ & $<0,001^{*}$ \\
\hline & $\begin{array}{l}X^{2}=5,33 \\
p=0,377\end{array}$ & $\begin{array}{l}X^{2}=9,11 \\
p=0,105\end{array}$ & \\
\hline
\end{tabular}

Her bir dikey sütunda aynı küçük harflerle gösterilen ortalamalar fark istatistiksel olarak anlamlıdır $(p<0,05)$.

* Her bir yatay sütunda aynı büyük harflerle gösterilen ortalamalar arası fark istatistiksel olarak anlamlıdır $(p<0,05)$.

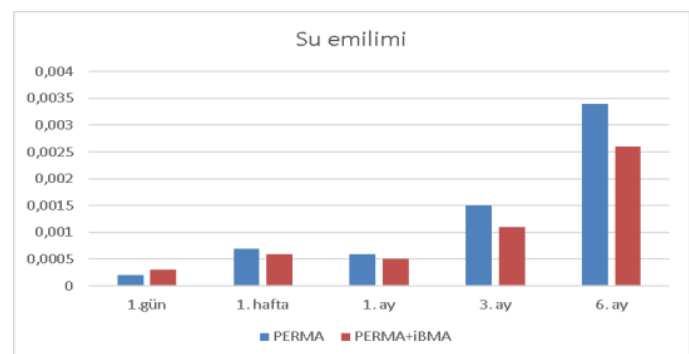

Grafik 1. Bekletme süresi ile su emilimi arasındaki ilişki grafiği

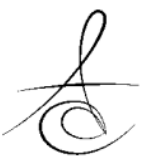




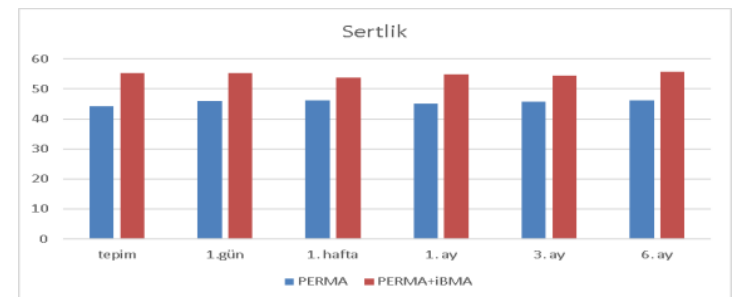

Grafik 2. Bekletme süresi ile sertlik arasındaki ilişki grafiği

\section{TARTIŞMA}

Bu çalışmada elde edilen sonuçlar doğrultusunda yumuşak astar materyalinin su içerisinde farklı süre zarflarında bekletilmesi su emilimi miktarını artırırken, Shore A sertlik değerini fazla değiştirmediği görülmüştür. Bu yüzden başlangıçta kurduğumuz hipotez reddedilmiştir.

Yumuşak astar materyalleri protetik uygulamalarda uzun süredir kullanılmaktadır, fakat sahip oldukları fiziksel özellikler tamamıyla tatmin edici değildir. Kısa süreli kullanımlarda su emilimi, renk değişikliği, çözünürlük ve sertlik özelliklerinde değişim görülmektedir. ${ }^{18}$ Özellikle bu değişimler akrilik esaslı yumuşak astar materyalinde daha fazla ortaya çıkmaktadır. Bu durumun, çalışmada kullanılan yumuşak astar materyalinin içeriğinde bulunan plastizer maddesinin za manla uzaklaşmasından kaynaklandığı düşünülmektedir. ${ }^{2,4,6}$ Literatürde yumuşak astarların fiziksel özellikleri üzerine yapılan çalışmalarda yumuşak astar materyallerinin sertliğinin ve su emilim değerlerinin güvenilir olabilmesi için uzun süreli klinik çalışmaların yapılmasının gerekliliği vurgulanmıştır. ${ }^{19-22}$ Yaptığımız çalışmada da silikon esaslı ve iBMA' Iı silikon yumuşak astar materyalini 5 farklı zaman diliminde sertlik ve su emilimi yönünden inceledik.

Akın ve ark. ${ }^{14}$ nın yumuşak astar materyali ile polimetilmetakrilat arasındaki bağlantıyı değerlendirdikleri çalışmada hidroksietilmetakrilat ve iBMA monomerleri içerisinde birer ve üçer $\mathrm{dk}$ bekletmişler ve en yüksek bağlanma değerini $3 \mathrm{dk}$ iBMA'da bekletilen yumuşak astar materyalinde tespit etmişlerdir. Çalışmamızda bu verilere dayanarak permaflex'i IBMA içerisinde 3 dakika bekletme yolunu tercih ettik.

Akrilik ve yumuşak astar materyallerinin farklı içecek ya da farklı antimikrobiyal ajanlarda bekletmenin renk değişimi, bağlanma, sertlik ve su emilimi üzerine etkilerinin araştıııldığı çalışmalar mevcuttur. 3,4,14,23,24 Ancak, iBMA'nın yumuşak astarların fiziksel özelliklerinde oluşturabileceği değişiklikleri incele- yen literatürde az çalışma mevcuttur. Tuğut ${ }^{25}$ ve Akın ${ }^{14}$ iBMA'lı yumuşak astar maddesinin akrilikle olan bağlantısı incelemiş ve İBMA ilavesinin bağlanma dayanımını önemli derecede artırarak olumlu bir etki yaptığını belirtmişlerdir. ${ }^{14,25}$ Yaptığımız bu çalışmada elde edilen veriler ışığında, iBMA ilavesinin yumuşak astar materyalinin su emilimini ve sertlik değerindeki değişimi azaltarak materyalin kullanımına olumlu katkı sağladığını söyleyebiliriz.

El-Hadary ve ark. ${ }^{26}$ akrilik ve silikon esaslı yumuşak astar materyallerini su içerisinde 1,4 ve 6 hafta bekletirken, yine benzer olarak Yanıkoğlu ve ark. ${ }^{27}$ silikon ve akrilik esaslı yumuşak astar materyallerini 1,4 ve 16 hafta tükürük, temizleyici ajanlar ve su içerisinde bekletmişlerdir. Her iki çalışmada da artan süreyle beraber emilim arttığı, en fazla emilimin su içerisindeki gerçekleştiği ve akrilik içerikli yumuşak astarın silikon içerikli olana göre daha fazla su emdiği belirtilmiştir. Çalışmamızda elde ettiğimiz veriler de bekletme süresindeki artışla doğru orantılı olarak su emilim miktarının arttığını gösterirken bu durum yukarıdaki çalışmaları da desteklemektedir. Ancak PERMA+ iBMA grubunun daha düşük su emmesini, iBMA' nın hidrofobik özelliğinden kaynaklandığını söyleyebiliriz.

Meşe ve ark $^{22}$ akrilik ve silikon esaslı yumuşak astar materyallerini 1 gün, 1 hafta, 1,3 ve 6 ay su içerinde beklettikleri çalışmada silikon esasılıları başlangıçta en düşük, 6 ay sonra en yüksek sertlikte olduğunu belirtirken, Pahuja ve ark $^{24}$ silikon ve akrilikleri esaslı yumuşak astarları 1 hafta, 1,3 ve 6 ay sodyum hipoklorit ve sodyum perborat içerikli dezenfektan da bekletmiş, kontrol grubu olarak yapay tükrük kullanmıştır. Silikon grubundaki sertlik artışının sadece 6 . ayda istatistiksel olarak anlamlı olduğunu vurgulamışlardır. Yaptığımız çalışmada da sertliğin en yüksek değerleri 6. ayda tespit edilirken istatistiksel olarak anlamlı bulunmamıştır. Bu durumun kullandığımız iBMA'nın kimyasal ve hidrofobik özelliğinden kaynaklandığını söyleyebiliriz.

Kim ve $a \mathrm{ark}^{28}$ yaptıkları çalışmada 6 farklı silikon astar maddesini 28 gün distile su içerisinde bekletmiş ve sonuç olarak tüm gruplarda sertlik miktarının arttığını ancak en az değişimin mucosoft materyalinde olduğunu belirtmişlerdir. Yaptığımız bu çalışma sonrasında elde ettiğimiz veriler yukarıdaki çalışmayı destekler niteliktedir. 


\section{SONUC}

Çalışmada, bekletme sürelerinin sertlik değerlerinde fazla değişiklik yapmadığı ancak su emilimini artırdığı görüldü. iBMA'nın da, su emilimine olumlu, sertliğe olumsuz etki yapmasına rağmen sertlik değerleri arası farkın çok olmaması sebebiyle materyal içerisinde kullanılabilir sonucunu çıkarabiliriz. Ancak in vivo olarak da çalışmanın yapılıp, sonuçlarında değerlendirilmesiyle yumuşak astar materyaline alternatif bir malzeme olarak düşünülebilir sonucuna varabiliriz.

Faik TUĞUT: ORCID ID: 0000-0002-6323-407X M. Emre COŞKUN: ORCID ID: 0000-0002-2430-5170 Türker AKAR: ORCID ID: 0000-0003-2035-8686

\section{KAYNAKLAR}

1. McCabe JF, Carrick TE, Kamohara H. Adhesive Bond Strength and Compliance for Denture Soft Lining Materials. Biomaterials 2002; 23: 1347-52.

2. Machado AL, Breeding LC, Puckett AD. Effect of Microwave Disinfection on The Hardness and Adhesion of Two Resilient Liners. J Prosthet Dent 2005; 94: 183-9.

3. Akşit KS, Mandalı G, Gürbüz Ö. Protetik Tedavide Bir Yumuşak Astar Maddesi; Molloplast-B. Atatürk Üniv Diş Hek Fak. Derg. 2012; 5: 113-22.

4. Leon BLT, Del Bel Cury AA, Rodrigues Garcia RC. Water Sorption, Solubility, and Tensile Bond Strength of Resilient Denture Lining Materials Polymerized By Different Methods After Thermal Cycling. J Prosthet Dent 2005; 93: 282-7.

6. Braden M, Wright PS. Water Absorption and Water Solubility of Soft Lining Materials for Acrylic Dentures. J Dent Res 1983; 62: 764-8.

7. Murata H, Taguchi N, Hamada T, McCabe JF. Dynamic Viscoelastic Properties and The Age Changes of Long-Term Soft Denture Liners. Biomaterials 2000; 21: 1421-7.

8. Yanıkoğlu N. Yumuşak Astar Maddeleri ve Özellikleri. Atatürk Üniv Diş Hek Fak Derg. 2004; 14: 55-64.

9. Pavan S, Filho JNA, Santos PH, Nogueira SS, Batista AUD. Effect of Disinfection Treatments on the Hardness of Soft Denture Liner Materials. J Prosthodont 2007; 16: 101-6.

10. Craig RG, Powers JM, Wataha JC. Dental Materials, Properties and Manipulation. 11th ed. St. Louis; Mosby: 2002. p. 668.
11. Parker S, Braden M. Water Absorption of Methacrylate Soft Lining Materials. Biomaterials 1989; 10: 91-5.

12. Tugut $F$, Akin $H$, Mutaf $B$, Akin GE, Ozdemir AK. Strength of The Bond Between A Silicone Lining Material and Denture Resin After Er:YAG Laser Treatments with Different Pulse Durations and Levels of Energy. Lasers Med Sci 2012; 27: 281-5.

13. Bolayır G, Demir H, Doğan A, Boztuğ $A$, Doğan OM, Soygun K. Effects of Different High Alkyl Methacrylate Monomers on Tensile Bond Strength Between Resilient Liner and Acrylic Resin. Mater Res Innov 2009; 13: 431-5

14. Akin $H$, Tugut $F$, Mutaf B, Guney U. Investigation of Bonding Properties of Denture Bases to SiliconeBased Soft Denture Liner İmmersed in İsobutyl Methacrylate and 2-Hydroxyethyl Methacrylate. J Adv Prosthodont 2014; 6: 121-5.

15. Johnson JA, Jones DW. The Mechanical Properties of PMMA and Its Copolymers with Ethyl Methacrylate and Butyl Methacrylate. J Mater Sci 1994; 29: 870-6

16. Sahin O, Ozdemir AK, Turgut M, Boztug A, Sumer Z. Investigation of Flexural Strength and Cytotoxicity of Acrylic Resin Copolymers by Using Different Polymerization Methods. J Adv Prosthodont 2015; 7: 98-107

17.Emileh A, Farahani EV, Imani M. Swelling Behavior, Mechanical Properties and Network Parameters of $\mathrm{Ph}$ And Temperature-Sensitive Hydrogels of Poly((2-Dimethyl Amino) Ethylmethacrylate-CoButyl Methacrylate). Eur Polymer J 2007; 43: 1986-95.

18. Chen, JT, Lin Y. Liquid-Liquid Equilibria of Water + 1-Butanol + Methyl Methacrylate or Butyl Methacrylate or İsobutyl Methacrylate at $288.15 \mathrm{~K}$ and 318.15 K. Fluid Phase Equilibra 2007; 259: 189-94.

19. Kawano F, Dootz ER, Koran A 3rd, Craig RG. Sorption and Solubility of 12 Soft Denture Liners. J Prosthet Dent 1994; 72: 393-8.

20. Kulak-Ozkan Y, Sertgoz A, Gedik H. Effect of Thermocycling on Tensile Bond Strength of Six Silicone-Based, Resilient Denture Liners. J Prosthet Dent 2003; 89: 303-10. 
21. Parr GR, Rueggeberg FA. In Vitro Hardness, Water Sorption, and Resin Solubility of LaboratoryProcessed and Autopolymerized Long-Term Resilient Denture Liners Over One Year of Water Storage. J Prosthet Dent 2002; 88: 139-44

22.Mese A, Guzel KG, Uysal E. Effect of Storage Duration on Tensile Bond Strength of Acrylic or Silicone-Based Soft Denture Liners to A Processed Denture Base Polymer. Acta Odontol Scand 2005; 63: 31-5.

23. Urban VM, Lima TF, Bueno MG, Giannini M, Filho AJ, Effect of The Addition of Antimicrobial Agents on Shore A Hardness and Roughness of Soft Lining Materials. Journal of Prosthodontics 24; 2015: 207-14

24. Pahuja RK, Garg S, Bansal S, Dang RH. Effect of Denture Cleansers on Surface Hardness of Resilient Denture Liners at Various Time İntervalsAn İn Vitro Study. J Adv Prosthodont 2013; 5: 2707

25. Tuğut $F$, Coşkun $M E$, Akın H. Farklı İçeceklerin Silikon Esaslı Yumuşak Astar Maddesi ile Kaide Rezini Arasındaki Bağlanma Direncine Etkisi. Turkiye Klinikleri J Dental Sci 2016; 22: 104-9

26. El-Hadary A, Drummond JL. Comparative Study of Water Sorption, Solubility, and Tensile Bond Strength of Two Soft Lining Materials. J Prosthet Dent 2000; 83: 356-61

27. Yanıkoğlu ND, Duymuş ZY. Comparative Study of Water Sorption And Solubility of Soft Lining Materials in the Different Solutions. Dental Materials Journal 2004; 23: 233-9

28. Kim B, Yang $H$, Chun M, Park Y. Shore Hardness and Tensile Bond Strength of Long-Term Soft Denture Lining Materials. J Prosthet Dent 2014; 112: $1289-97$

\section{Yazışma Adresi}

Dr. Öğr. Üyesi Faik Tuğut

Cumhuriyet Üniversitesi, Dişhekimliği Fakültesi, Protetik Diş Tedavisi Anabilim Dalı,

58140, Sivas.

Tel: 0346 2191010-2799

Fax: 03462191237

E-mail: tugut78@hotmail.com 